\section{El otro como espécimen. Los usos de la fotografía del siglo XIX para la construcción del otro}

Valeria Stefanini *

Resumen: Históricamente distintas disciplinas han utilizado la fotografía para ilustrar sus avances en investigación y sus discursos, la fotografía ha estado al servicio del texto y de la reflexión sin que se profundice en ella como objeto de estudio autónomo.

Las fotos con las que nos proponemos trabajar no han tenido una suerte muy distinta, desde el momento mismo de su creación se debatió acerca de cuál era el lugar que estas ocuparían en relación al objeto representado, o sea cuán fielmente se imprimían en la foto las características del cuerpo del otro que al investigador le interesaba luego reconocer en su estudio.

Las fotografías que realiza Carlos Bruch de las distintas comunidades indígenas (tanto en el norte de la Argentina como en el sur) dan cuenta de una concepción acerca de la fotografía, pero también nos permiten pensar en una concepción que el fotógrafo explicita acerca de los habitantes del país y acerca de la ciencia como posibilidad de ordenamiento y comprensión del mundo.

Esa es la relación que nos proponemos abordar en este trabajo, la relación entre el dispositivo fotográfico, un otro que está siendo representado y construido por esa representación y los discursos científicos que permiten que eso suceda y le brindan el contexto teórico como para que suceda en el ámbito institucional de un museo nacional de ciencias naturales.

Palabras clave: Discurso científico - Fotografía - Cuerpo - Construcción del Otro - Museos de ciencias naturales

[Resúmenes en inglés y portugués en las páginas 186 -187]

${ }^{(*)}$ Licenciada en Artes por la UBA y la Universidad de Chile, posgrado en Gestión Cultural por la Universidad de Chile, actualmente está realizando la Maestría en Sociología de la Cultura y Análisis Cultural en la UNSAM. Sus áreas de interés e investigación son: ética y fotografía, el uso del cuerpo y relaciones entre estudios de género y la representación del cuerpo y la fotografía. Docente de historia del arte y ética en universidades y escuelas de arte, diseño y fotografía. 


\section{El otro como espécimen. Los usos de la fotografía a fines del siglo XIX para la construcción del otro}

A fines del siglo XIX tanto la comunidad científica internacional como personas particulares estaban ansiosas por poder ver imágenes de los distintos miembros de las diferentes comunidades indígenas que poblaban la Argentina. A medida que el tiempo pasaba la sensación de que estos grupos desaparecerían o en su defecto se mimetizarían con otros y perderían sus características diferenciadoras reforzaba la prisa por construir álbumes de imágenes que apresaran esta información. Frente a una realidad que se presuponía cambiante y dinámica el investigador debía orquestar los modos de apresar los datos necesarios para luego, tanto él como otros científicos que desde lugares distantes sentían curiosidad por conocer la vida en nuestro territorio, poder investigarlo.

La misión de los Museos de Ciencias Naturales a fines del siglo XIX era la investigación y el resguardo de la mayor cantidad de datos que se pudieran almacenar. Esta colección de datos en el caso de los grupos humanos que interesaba investigar se organizaba alrededor de piezas, como podían ser restos óseos, objetos producidos (sobre todo cerámicas y textiles), dibujos, grabados, fotografías y también especímenes vivos que se mantenían cautivos en los museos para ser observados.

En nuestro caso particular el Museo de Ciencias Naturales de la Plata (MLP) informa que "fue creado por un decreto del Gobierno de la provincia de Buenos Aires el 19 de septiembre de 1884, en base a un proyecto del coleccionista Francisco Pascasio Moreno (1852-1919) quien se desempeñó como Director hasta 1906. Las primeras colecciones provinieron del Museo Antropológico de Buenos Aires creado en 1877, con patrimonio donado por el propio Moreno." El museo funciona como una prolongación de la ideología $\mathrm{y}$ de los intereses de su fundador, que unifica sus propias colecciones, biblioteca y contactos con las del museo, transformándolas en una sola.

El Museo de Ciencias Naturales de la ciudad de La Plata va a ser un lugar privilegiado de creación, guardado y exhibición de grandes cantidades de fotografías a finales del siglo XIX. En sus archivos se encontraron un gran número de imágenes en las que aparecen representadas personas provenientes de distintos pueblos originarios. Algunas de ellas fueron trasladadas a la institución en contra de su voluntad y en el medio de campañas bélicas de apropiación de territorios, como por ejemplo durante la llamada "Conquista del desierto" de 1878, campaña que según el historiador Osvaldo Bayer dejó un saldo de 14000 indígenas muertos y 14600 tomados como prisioneros para trabajar como esclavos. Algunas de estas personas privadas de su libertad pasaron sus últimos años cautivos en el Museo de Ciencias Naturales obligados a trabajar y fueron recluidos para ser estudiados y exhibidos ante investigadores nacionales y europeos. Sus restos permanecieron en este o en otros museos como parte de las exposiciones y de investigaciones de carácter científico. En 1887 frente a la muerte de "tres indios de las dos familias que allí viven por cuenta del gobierno" el diario La Capital el día martes 27 de septiembre hace una denuncia en un artículo "que da cuenta de tres muertes y sus respectivas inhumaciones dentro del MLP: Margarita Foyel, el 23 de septiembre; una niña de 7 años el día 25 (esta muerte no ha sido mencionada en ninguna publicación) y el cacique Inacayal el día 26." (Oldani, 2011) La 
preocupación del diario es que los trabajos sobre los cuerpos se realizaron sin mediar la presencia de ninguna autoridad, lo primero que se denuncia es,

$1^{\circ}$ Hace cuatro días que murió una india hija de uno de los dos caciques que con sus familias, se tienen allí. El cadáver de esta mujer ha sido desollado allí mismo, al objeto de disecar su esqueleto. En el cuarto del escultor está en yeso y modelados en el mismo cadáver, la cara, una mano y un pie, de la muerta. La masa informe de los músculos fue sacada por el empleado Sabino Domínguez, portero del Museo. ¿Dónde la enterró...?

La pregunta que plantea el diario y que queda en suspenso es importante ya que da cuenta de que los museos en sus investigaciones se manejan por fuera de los requerimientos de la ley, y que los cuerpos con los que trabajan no revisten los mismos derechos que cualquier otro cuerpo que se hubiera hallado muerto en algún otro lugar.

Al hacerse pública la información el señor Francisco P. Moreno, director del Museo, se ve obligado a dar explicaciones al Sr. Comisionado en una carta que se publica en el mismo diario, la carta tiene algunos puntos interesantes que nos permiten comprender el sentido de las investigaciones que se desarrollaban sobre los miembros de los pueblos originarios argentinos. En primer lugar Moreno señala la importancia de estos cuerpos para la investigación "lo hice dado el interés escepcional (sic) que para la ciencia antropológica tendrían estas disecciones, por tratarse de los últimos representantes de razas que se estinguen (sic) y de las que no se han hecho estudios todavía., el paso del tiempo angustia a los investigadores que sienten que están frente a realidades irrepetibles. Continúa Moreno explicando la importancia del trabajo sobre los cuerpos y exhibición de los restos vinculándolo directamente con la función del museo,

Hubiera sido demostrar verdadero atraso en el movimiento cien-tífico del día, el no haber disecado estos cadáveres, pues hubiéranse perdido valiosísimos materiales de estudio que tanto van a contribuir al conocimiento exacto de la constitución étnica de las razas americanas y sobre todo cuando es precisamente el Museo de La Plata el que está destinado a ser el centro de esta clase de investigaciones.

De manera sintética estos párrafos nos permiten intuir los fines que se persiguen en la realización de estas actividades, las personas se estudiaban vivas y cuando fallecían se seguían estudiando sus cuerpos. En la carta Moreno solamente manifiesta comprensión de la utilidad de estas personas vivas sin mediar sentido ético o afectivo, “....se ha tratado y se trata de hacer que los indios que viven en el museo tengan la más larga existencia, la que es preciosa para observaciones lingüísticas y etnográficas sobre razas tan difíciles de examinar en sus medios salvages (sic)." El indio es útil vivo para investigación pero si la muerte llega a acontecer su función de espécimen de análisis no cambia.

Frente a estos claros objetivos la fotografía parecía poder cumplir con una función de registro fiel del otro y presenta la capacidad de detener las características cambiantes fi- 
jándolas en un momento determinado y de este modo evitar los cambios producidos por el paso del tiempo y con él las variaciones que se estaban provocando en las distintas comunidades originarias al incorporarlas al sistema de trabajo, religión y organización del nuevo Estado Argentino.

En este texto trataremos de concentrarnos en responder a la pregunta por la relación entre la fotografía y la construcción del otro, específicamente: ¿Cuáles son los usos de la fotografía de fines del siglo XIX para la representación y construcción de una idea de "otro" en el cuerpo de las poblaciones indígenas? Partiendo del supuesto de que la fotografía funcionó de diversas maneras para la construcción del otro y que sus usos son plurales construimos un corpus de fotos con piezas que fueron encontradas en el Museo de Ciencias Naturales de la Plata, usando como base el trabajo realizado por el colectivo GUIAS (Grupo Universitario de Investigación en Antropología Social).

Esto se debe en primer lugar a que somos deudores del esfuerzo que el Colectivo GUIAS de la Universidad de La Plata viene realizando desde el año 2006, en el que asumieron la tarea de iniciar la organización del acervo fotográfico del museo y sobre todo de emprender una investigación profunda y sistemática sobre los restos óseos de cuerpos humanos que se encontraban en el Museo de Ciencias Naturales de La Plata con la intensión de lograr sacarlos de la exhibición pública con miras a su posterior restitución. El trabajo del Colectivo GUIAS es un referente significativo por su investigación y por los avances obtenidos en las restituciones de cuerpos a sus comunidades de origen.

Desde el año 1994 en la Argentina se comenzó un lento proceso de restitución y algunos restos de las personas cuyos cuerpos estaban en exhibición o guardados en el depósito del Museo de Ciencia Naturales, ya pudieron volver a sus comunidades y esos muertos pudieron ser llorados y enterrados según sus ritos y tradiciones. El $1^{\circ}$ de septiembre de 2006 se aprobó el retiro de exhibición de todos los restos de humanos de las comunidades y la restitución complementaria del cacique Inacayal, (ya que la restitución de su cuerpo de 1994 había sido parcial) que se pudo efectivizar recién el año pasado valiéndose de la Ley Nacional 25.517. También se logró que todos los restos que tenían identificación no pudieran seguir siendo estudiados por la comunidad científica, como hasta ese entonces, sin mediar el permiso y consentimiento expreso de las comunidades de origen o familiares.

\section{La foto como apoyo a las ciencias naturales}

Nos proponemos pensar la imagen fotográfica desde su densidad histórica y problematizarla (Tell, 2017), pensar la foto en vinculación con las distintas ideas que las estaban atravesando y constituyendo y por sobre todas las cosas pensar estas fotos en su relación con una realidad a la que revelan y constituyen simultáneamente, pensar la foto no como un modo de ilustrar la realidad y la historia del pasado sino como una posibilidad de comprenderla, trabajar con la foto como una "puerta de acceso" (Tell, 2017) a la mentalidad de una época y a los discursos que en esta circulaban.

Este lugar en el que nos proponemos colocar a la fotografía para su análisis no es el que suele ocupar en los estudios sobre el pasado. Creemos que, en gran medida, esto se debe 
a que se piensa en la foto como un simple registro de la realidad, motivo por el cual no parece necesario ni útil problematizarla ni reflexionar acerca de esta.

Los usos de la fotografía a mediados del siglo XIX son múltiples y muy complejos, en este escrito vamos a tratar de reflexionar sobre la vinculación de la foto con las investigaciones producidas en museos de ciencias naturales para representar e investigar a comunidades indígenas locales, pero este es solo uno de los múltiples aspectos que van a vincularse con la foto decimonónica.

El MLP se organiza alrededor de la figura de su fundador, su gestión y perseverancia darán como consecuencia la fundación del lugar que inicia con las colecciones particulares de Moreno que luego serán donadas por él al museo. La información institucional del museo da cuenta de que Moreno, “... en 1882 emprendió un viaje por las provincias de Cuyo y Chile, donde armó colecciones arqueológicas y confeccionó un álbum fotográfico con el objeto de promocionar, ante los poderes públicos, las actividades desarrolladas en el trayecto y encontró un nuevo destino para las colecciones depositadas en Buenos Aires.” Desde antes de la fundación del museo Moreno ya comprende que la fotografía tiene un rol significativo que acerca a la Capital (donde se toman las decisiones) el mundo que está más allá de esos límites, el uso de la foto en este párrafo se plantea como estratégico o promocional, una manera de dar a conocer y atraer la atención.

Alejandro Martínez (2010) releva que las primeras fotos que encontramos en el museo fueron encargadas a fotógrafos profesionales de la casa Samuel Boote, luego fue el personal estable del museo quien se encargó de fotografiar, Hermann tate Kate, Charles de La Hitte, Robert Lehmann-Nitsche, Carlos Bruch, entre otros,

Además, para 1889 ya habían comenzado a funcionar los talleres de publicaciones contiguos al museo donde se encontraba funcionando un laboratorio de fotografía que llevaba a cabo trabajos de obtención, revelado, copia e impresión de imágenes fotográficas para las publicaciones científicas editadas por el museo, que se encontraba a cargo de Carlos Bruch, quien se desempeñaría allí como fotógrafo y fototipista, entre 1887 y 1900. (pág. 16)

Las fotografías en las que nos vamos a concentrar fueron realizadas por el fotógrafo y entomólogo alemán Carlos Bruch tanto en sus viajes por el territorio argentino como dentro del edificio del museo, con la intención de producir un registro de las características de las diferentes "razas nacionales". Bruch viajó como empleado del museo y también de manera independiente con la intención de producir un registro y buscar especímenes que luego ofrecería en venta al museo. En una carta que Bruch le escribe a Samuel Lafone Quevedo en diciembre de 1910 (Martínez, 2010) el fotógrafo ofrece su material a la venta en el museo y menciona que su obra se conforma por "vistas de paisajes, gentes, animales y costumbres del país, tomadas en gran parte personalmente durante los viajes a la Patagonia y provincias del Norte."

Los paisajes, animales, personas y costumbres se ubican todos en el mismo nivel de interés e importancia y no se menciona que recibieran un tratamiento diferente en el registro, las personas y las cosas son todos objetos de estudio interesantes para el investigador. 
Luego de que en 1735 Linneo publica su texto El sistema de la Naturaleza la difusión de sus teorías será muy rápida, y en pocos años muchos naturalistas viajan por el mundo con la intención de proponer un orden a la pluralidad que encuentran. El rol de la ciencia es sacar lo natural de la naturaleza, aislarlo para estudiarlo y mirarlo con ojos europeos con la idea de beneficiar a este "nuevo mundo" con un orden. Se subsume la historia y la cultura dentro de la naturaleza, pero no toda la cultura sino especialmente la cultura del otro. "Aquí el nombrar, el representar y el reclamar son una sola cosa; el acto de nombrar produce la realidad del orden." (Pratt, pág. 68) En ese afán el europeo que llega a América encuentra los distintos elementos que va a considerar como especímenes, los clasifica y les da nuevos nombres, nombres europeos, no importa si este espécimen es vegetal, mineral, animal o un ser humano.

Esta utilización de un grupo de habitantes del país como especímenes que se estudian con procedimientos relacionados con las ciencias naturales da origen a una pregunta central de esta investigación que trata de indagar acerca de los distintos discursos que construyen estas fotografías. ¿Cuáles son los discursos que la atraviesan y de qué manera construyen la condición de posibilidad de las fotografías sacadas por Carlos Bruch a miembros de los pueblos originarios de la Argentina que se realizaron a fines del siglo XIX?

Es importante, pero excede a este análisis, comprender cuáles son los modos de producción y la circulación de estas fotografías para entender cómo se construyeron y que parámetros estaban condicionando su conformación, cuáles son las decisiones que tomó el fotógrafo y en función de qué reflexiones estuvieron motivadas. La recepción y circulación de estas fotos no solo fue en la Argentina, ya que muchas de ellas, sueltas o en álbumes, viajaron a Europa en donde ayudaron a organizar la mirada que desde allí se construía acerca de la historia americana. Esas indagaciones quedaran para ser abordadas en el futuro.

Lehmann-Nitsch menciona en esta cita la importancia clave que le asignó a la fotografía para el estudio de las razas americanas, (Martínez, 2010. Pág. 116)

La PARTE FOTOGRÁFICA de nuestro trabajo desempeña efectivamente un papel principal en la presente obra [...] Para la descripción se adoptaron formularios breves que contenían solamente aquellos rasgos que no resaltan del estudio de la fotografía. Integrar por completo los formularios que se recomiendan en los gabinetes de antropología, exige demasiado tiempo, y no da tampoco mayores resultados; mientras que la fotografía por el contrario, permite, sin palabras de más, y con ahorro de tiempo, un estudio prolijo en el gabinete, en el que uno puede trabajar con toda tranquilidad.

La foto se vincula con la curiosidad científica de la época y también se inscribe en una problemática política y económica que se manifiesta alrededor de la campaña militar de la Conquista del Desierto.

Tell (2017) al hablar de las fotografías que se realizaron durante la Conquista del Desierto con fotógrafos como Pozzo que acompañaron a los ejércitos en su invasión, vincula la cámara fotográfica con otros instrumentos de conquista como el tren. “...el dispositivo fotográfico mismo constituía un atributo con carga simbólica. El dominio sobre el terri- 
torio y sobre el indio no se apoyaba solo en la representación, sino también en la imagen fotográfica evidenciada como objeto construido." (pág. 52) La posibilidad de tomar decisiones acerca de cómo va a ser representado el otro y construir la escena fotográfica es un ejercicio de poder sobre el otro al que este se somete. La conquista es del territorio, de los cuerpos y de la libertad de elegir mostrarse o no y cómo.

No es solo la foto y las decisiones que sobre ésta se toman lo que construye una relación entre fotógrafo/científico y sujeto representado sino también el hecho de portar una cámara como instrumento que viene a representar la tecnología y recursos que son occidentales lo que colocan al otro en un lugar se sumisión. Lugar que Tagg (1988) llamará pasivo o feminizado, cuando los ve como "Sometidos a una mirada escrutadora, forzados a emitir signos, pero apartados del control del significado, esos grupos eran representados e intencionalmente mostrados como incapaces de hablar, actuar u organizarse por sí mismos." (pág. 20) En este sentido es interesante la construcción de la imagen del cacique Pincén por Antonio Pozzo. Pese a que Pincén se encontraba cautivo es fotografiado con una lanza en la mano, haciendo una puesta en escena de la ferocidad que el blanco le atribuía, pero la lanza es un préstamo de las colecciones particulares de Moreno y será para Pincén solo un vestuario teatral propuesto por otros para construir un personaje que él no había inventado; como señala Tagg, Pincén emite signos que no fueron construidos por él.

Mary Louise Pratt (1997) aventura una explicación interesante para este tratamiento,

En medio de la actual crítica erudita de los discursos colonialistas los lectores contemporáneos no pueden dejar de vincular esta creación de un cuerpo mudo, desnudado, biologizado, con la mano de obra desarraigada, desposeída, descartable que los colonialistas europeos tan despiadada e incansablemente lucharon por crear en sus asentamientos en el exterior. (pág. 100)

Martínez (2010) también piensa acerca del papel que jugó específicamente la foto,

La fotografía por esos años no era considerada como un medio puramente ilustrativo sino que se pretendía usarla como prueba empírica, como dato científico que sirviera de apoyo a las teorías sobre el origen y la diversidad de las "razas humanas... la fotografía le aportó a la ciencia del siglo XIX, un cambio en los modos de representación, la ilusión de haber conseguido un medio para llegar a la objetividad. (pág. 7)

\section{La foto como prueba de verdad}

Para poder problematizar la fotografía esta va a ser pensada como un punto de vista acerca del otro que habla tanto del fotógrafo como del medio cultural en el que está inserto, "No se toma una foto, se la hace." (Soulages, 2010) Vamos a centrar la atención en las condiciones técnicas y discursivas de producción, en el contexto en que se realizaron y que- 
daran por investigar en otro momento sus modos de exhibición, difusión, circulación y recepción para poder comprender cabalmente cómo se produjeron estas fotos y que ideas y conceptos acerca del otro, de la foto y de la ciencia construyeron a fines del siglo XIX. Las fotos producidas por Carlos Bruch en el marco de su trabajo en el MLP responden a diferentes estrategias de concepción de la fotografia. Por un lado encontramos imágenes que hacen enfasis en su literalidad, en las que aparecen sujetos representados con intensiones de trasmitir una idea objetiva en la que la emocionalidad del fotografo se ve borrada, por el otro lado hay un grupo de imágenes en las que los sujetos representados se muestran en su entorno, rodeados de objetos y personas y se busca trasmitir cierta concepción acerca de la vida y ocupaciones del otro. Pero cualquiera de los casos que nos encontremos se caracteriza por trasmitir la certeza de que lo que se está mostrando es un fragmento del mundo elegido por la mirada formada del científico ya que es relevante de rescatar del olvido. La fotografía asi pensada asigna importancia a lo que enfoca por la autoridad de la ciencia que la construye. "Fotografiar es conferir importancia", refuerza Susan Sontag (pág. 38) La foto funciona como selección, registro, prueba y como documento.

Teóricos de la foto han trabajado especialmente acerca del problema de la representación ya que el vínculo entre la foto y lo representado es constitutivo al lugar social, artístico y científico que ha ocupado.

John Tagg (1988) sostiene,

...la combinación de evidencia y fotografía en la segunda mitad del siglo XIX estaba estrechamente ligada a la aparición de nuevas instituciones y nuevas prácticas de observación y archivo: es decir, esas nuevas técnicas de representación y regulación que tan escenciales fueron para la reestructuración del Estado local y nacional en las sociedades industrializadas de aquellas épocas y para el desarrollo de una red de instituciones disciplinares - policía, prosiones, manicomios, hospitales, departamentos de salud pública, escuelas e incluso el propio sistema fabril moderno-. (pág. 12)

Susan Sontag (1989) piensa las fotos de la siguiente manera, "En realidad, las fotografías son experiencia capturada y la cámara es el arma ideal de conciencia en su afán adquisitivo. ...Fotografiar es apropiarse de lo fotografiado." (pág. 14) Fotografiar al indígena es apropiarse de una realidad que estaba en vías de desaparecer por acción del avance militar en afán de ocupar los territorios, los científicos saben que la realidad en la que ellos viven, sus costumbres y características no se mantendrán una vez que sean expulsados de sus tierras, así que lo que apresa la foto no es solo al otro sino la historia, el tiempo y el territorio, todo condensado en un rectángulo.

La comparación de Sontag que relaciona la cámara con un arma en el caso de nuestras fotos es muy esclarecedora. Cuando lo que se está registrando son sujetos que por acción de una campaña militar se encuentran cautivos o desplazados y son fotografiados sin que ellos lo puedan realmente evitar, lo que estamos viendo es un ejercicio de poder, político y cultural, que el grupo vencedor realiza sobre el grupo vencido. 
Francois Soulages (2010) refuerza el planteo de Sontag y nos dice que "Cualquiera que sea la fotografía no nos dice tanto la verdad del objeto como el punto de vista del sujeto que fotografía." (pág. 54) es por eso que los retratos de Inacayal en el museo nos hablan de Inacayal y de los tehuelches y también de Carlos Bruch, de la historia originaria y de la historia de la ciencia, nos hablan del museo y de las ideas que dieron forma a la construcción de la Argentina, una foto puede narrarnos la historia nacional.

Philippe Dubois (1986) recupera la idea planteada por Pierre Bourdieu quién apunta en Un art moyen en 1965 ,

Por lo general se está de acuerdo en que la fotografía es el modelo de la veracidad y la objetividad (...). Es demasiado fácil mostrar que esta representación social tiene la falsa evidencia de los preconceptos; de hecho, la fotografía fija un aspecto de lo real que no es otra cosa que el resultado de una selección arbitraria, y, en ese sentido, una transcripción: entre todas las cualidades del objeto, sólo se retienen las cualidades visuales que se dan en el instante y a partir de un punto de vista único; estas son transcritas en blanco y negro, generalmente reducidas y proyectadas en el plano. Dicho de otra forma la fotografía es un sistema convencional que expresa el espacio según las leyes de la perspectiva (habría que decir, de una perspectiva) y los volúmenes y los colores por medio de degradados del negro y del blanco. Si la fotografía es considerada como un registro perfectamente realista y objetivo del mundo visible, es porque se le ha asignado (desde el origen) unos usos sociales considerados "realistas" y "objetivos". Y si se ha presentado inmediatamente con las apariencias de un "lenguaje sin código ni sintaxis", en resumen de un "lenguaje natural", es ante todo porque la selección que opera en el mundo visible es totalmente apropiada a su lógica, a la representación del mundo que se impuso en Europa desde el Quatrocento. (pág. 37)

Como se puede ver no todos piensan la relación entre la fotografía y la representación del mismo modo, y el problema de la objetividad de la fotografía es hasta el día de hoy un problema significativo. Sorlin (2004) señala que ya en 1866 "Flaubert explicaba a Taine que una 'prueba fotográfica' siempre lo sorprendía porque lo que veía en ella nunca era lo que él mismo había observado." (pág. 36) Pero estas voces que iniciaban una sospecha siempre fueron pocas y menores, en general en el siglo XIX y hasta el día de hoy la foto nos atrae con su prueba de verdad, por más que racionalmente la podamos cuestionar siembra una duda en nuestro espíritu, por que todos sabemos que de alguna manera eso que vemos, aunque sea con otros sentidos y explicaciones posibles, estuvo ahí. Como plantea Soulages una foto es una huella, pero ¿una huella de qué? 


\section{Poner en grupos. La raza como principio de clasificación}

Para comprender estas fotografías debemos entender que ha habido una intención de división de la humanidad en fragmentos para organizar esa totalidad que parecía informe en grupos que son excluyentes los unos de los otros y jerárquicamente posicionados. Esto permitió que se genere el extrañamiento suficiente como para que un grupo decida estudiar al otro como si fueran muestras de especímenes totalmente diferentes. Tal y como plantea Judith Butler (2010) lo que no se reconoce aquí es el "nosotros".

La antropóloga Diana Lenton en una entrevista para Página 12 (Aranda, 2011) expone que sin duda hay distintos factores por el que estos grupos humanos son vistos como un otro que no se valora y que se construye como imposibilitado de acceder a los mismos derechos, pero la diferencia racial es un factor preponderante,

Sin duda tiene que ver la clase social víctima, pero sobre todo hay una mirada racista dentro de lo que es el sentido común argentino. La sociedad argentina es racista respecto de los pueblos originarios. Se piensa que lo que sucede con otras personas no es tan importante, por eso hay dolores que no nos conmueven y otros que sí. Para mucha gente un campo de concentración se define como tal cuando ahí adentro hay gente que se parece a mí, si no, no es un campo de concentración.

Judith Butler (2010) en su libro Marcos de Guerra reflexiona acerca de la violencia selectiva y diferencial y de los distintos parámetros que se construyen para mirar al otro. $\mathrm{Su}$ preocupación es acerca de estas vidas, "Si ciertas vidas no se califican como vidas o, desde el principio, no son concebibles como vidas dentro de ciertos marcos epistemológicos, tales vidas nunca se considerarán vividas ni perdidas en el sentido pleno de ambas palabras." (pág. 13) La pregunta que se hace obligatoria es entonces ¿qué es una vida? Y la respuesta es profundamente compleja, ya que no es un debate que se pueda dar en términos biológicos ni puramente sociales, ni exclusivamente políticos, las consecuencias de cada uno de los encasillamientos posibles son enormes. En este texto Butler piensa acerca de esas vidas que no son reconocidas como vida, y por consiguiente sus muertes no son reconocidas como tales ni hay un duelo que las llore.

El texto de Butler plantea un sinfín de cuestiones que pueden ser muy interesantes para pensar el caso en particular de este corpus de fotos, de estas propuestas de análisis solo vamos a tomar una que es la reflexión que gira en relación con el duelo. Butler entiende el duelo como un modo de dar valor a una vida, la vida que mereció ser vivida, que fue amada es la vida que será luego llorada. "Una vida que no es merecedora de ser llorada es una vida que no puede ser objeto de duelo porque nunca ha vivido, es decir, nunca ha contado como una vida en realidad." (pág. 64) El duelo es un modo de restauración de la vida y es por eso que el duelo es un acto público que se hace a la vista de otros como un modo de manifestar que esa vida que se ha ido estuvo cargada de sentido.

La acción de transformar los cuerpos que estaban clasificados como "piezas de museo" en cuerpos humanos es un acto de restitución de sentido mediante el cual se devuelve la humanidad a aquellos que habían sido privados de esta definición. 
Más allá de esta re significación, que es de vital importancia, el paso siguiente es la restitución que esas piezas de museo ahora transformadas en cuerpos humanos para que puedan ser lloradas en sus comunidades, para darle sentido a la vida que tuvieron y buscar un resarcimiento posible y lejano por la cruel muerte que padecieron.

Butler reflexiona especialmente acerca de las fotografías, "al enmarcar la realidad, la fotografía ya ha determinado lo que va a contar dentro del marco, un acto de delimitación que es interpretativo con toda seguridad. " (pág. 100-101) la fotografía es "una escena estructuradora de la interpretación".

La utilización y manipulación de seres humanos con intenciones vinculadas a una concepción de la ciencia decimonónica europea implica la creencia de un mundo dividido en partes que se enfrentan, establece que hay uno que se enfrenta a un otro que le es profundamente desconocido por que es diferente y es por eso que siente una necesidad de estudiarlo. Esto también implica que el científico occidental entiende que todos esos otros que descubre son iguales entre ellos (y es eso lo que le permite pensar que pueden ser catalogados de manera homogénea), pensar el mundo en función de esta dualidad significa diferenciar, oponer y obviamente jerarquizar.

Martínez (2010) cita las propias palabras de Robert Lehmann-Nitsche ${ }^{1}$ para explicar cuáles son los objetivos que tiene la antropología física de la época "buscar la forma típica del cuerpo de la raza."(pág. 110) y que es lo que entiende por raza, "un grupo somático, caracterizado por cierto número de rasgos comunes á todos los individuos que lo componen; es, pues, una unidad que puede variar en cierto grado entre sus dos extremos". (pág. 111) Para Lehmann-Nitsche la raza existe efectivamente en la naturaleza y su esencia puede ser capturada por la observación y puede ser registrada por el investigador (de aquí la importancia del dispositivo fotográfico).

Es interesante contrastar la definición de raza que manejaban los investigadores de fines del siglo XIX con miradas diferentes y contemporáneas para poder pensar de qué modo estas construcciones decimonónicas vieron al otro y de qué modo construyeron su objeto de estudio.

El siglo XIX se acerca a su objeto de estudio como si este estuviera esperándolo afuera, y pudiera ser mirado de manera objetiva y cuando se acerca, lo investiga, lo registra y sin percibirlo lo construye.

Achille Mbembe (2016) entiende la raza no en términos biológicos sino como selección de sujetos y planteo de nuevas formas de explotación, y cuando explica al negro como construcción de sentido plantea que,

... el negro fue inventado para significar exclusión, embrutecimiento y degradación, inclusive para significar un límite conjurado y aborrecido al mismo tiempo. Despreciado y profundamente deshonroso, en el contexto de la modernidad fue el único ser humano cuya carne fue transformada en cosa y su espíritu, la cripta viviente del capital, en mercancía. (pág. 33)

La ciencia se pone al servicio de esta invención reforzando el concepto de exclusión con investigaciones y exhibiciones preparadas en museos nacionales. Esa invención deja de ser una opinión subjetiva cuando el discurso científico la corrobora y la avala. El indio es otro 
ajeno al investigador y hay que desentrañar a cualquier precio su constitución, midiéndolo, pesándolo, probándolo, observándolo. Se le construye un lugar de espécimen peligroso y por eso las cadenas y la reclusión y por eso posa en las fotos cual un animal de zoológico. En contraposición a lo que nos decía Lehmann-Nitsche, Mbembe plantea que "la raza no existe como acontecimiento natural, físico, antropológico o genético. Sin embargo, tampoco se trata únicamente de una ficción útil, una construcción fantasmática o una proyección ideológica cuya función es la de desviar la atención de conflictos considerados más verdaderos." (pág. 40) En la Argentina podemos rastrear que la degradación de los miembros de los pueblos originarios viene de la mano de la apropiación del territorio, no solo porque se buscó pensar el territorio como vacío a la espera de que el blanco lo pueble sino porque se entendía que había seres que no se consideraban culturales, no se reconocía que su lengua fuera un idioma, ni que sus creencias y grupos fueran religiones, sistemas de organización, gobierno o familia, tampoco se veía que sus producciones tuvieran algo que ver con el talento, destreza y mucho menos con la inteligencia, la belleza o con el arte. En pocas palabras no tenían idioma, ni organización política ni familia ni ninguna producción física que demostrara talento como para ser considerados humanos en igualdad de condiciones.

Mbembe nos dice" Producir al negro es producir un lazo social de sumisión y un cuerpo de extracción, es decir, un cuerpo completamente expuesto a la voluntad de un amo que se empeña en obtener de él la máxima rentabilidad.” (pág. 52) El diario La Nación de octubre de 1878 anunciaba un reparto de indios mencionando que: "Las indias aún salvajes pueden ser útiles en tareas domésticas en las residencias de las familias porteñas." Demostrando que el mismo análisis que ocupa a Mbembe para pensar al negro puede servir en la Argentina para pensar al indio.

Esta construcción del indio como espécimen surge de la mano de la mirada de los primeros científicos viajeros que se adentran al territorio americano con la doble intención de conocer y dominar, o mejor expresado de conocer para entonces poder dominar. Es por esto que el indio fue visto como mercancía útil como fuerza de trabajo, como sobrante que hay que desplazar para poder ocupar sus territorios o como un ser exótico y llamativo aplicándosele una mirada romántica. El europeo que se acercó a conocer las comunidades americanas no lo hizo con la intensión de conocerlas en sí mismas sino de adecuarlas a las necesidades del mercado europeo que consumía historias, dibujos, cuadros y especímenes vivos o disecados.

Lo significativo es el rol de la ciencia en la producción de sentido y cómo se busca el discurso científico para avalar la explotación y apropiación del indio, sus riquezas y sus tierras. En el caso anterior la construcción de la oración está cargada de sentido, las indias son "aún salvajes" lo que esboza una tenue luz de esperanza de que puedan aprender a ser civilizadas (entendiendo civilización como los modos y costumbres provenientes de Europa) y es interesante la contraposición entre indias solas y familias porteñas, los indios llegan forzados a la ciudad y se los piensa carentes de vínculos afectivos lo que permite separarlos de sus hijos, padres, parejas, amigos. En la operación de alejarlos de los suyos se busca alejarlos también lo más posible del sentido de un ser social que es como se definía con orgullo un porteño de la época, en cambio los indios son solos, y esto es muestra cabal de su animalidad. 
Felipe Pigna en un artículo cita las palabras del Ingeniero Trevelot quién había sido un testigo ocular de la época,

Los indígenas han probado ser susceptibles de docilidad y disciplina. En lugar de masacrarlos para castigarlos sería mejor aprovechar esta cualidad actualmente enojosa. Se llegará a ello sin dificultades cuando se haga desaparecer ese ser moral que se llama tribu. Es un haz bien ligado y poco manejable. Rompiendo violentamente los lazos que estrechan los miembros unos con otros, separándolos de sus jefes, sólo se tendrán que tratar con individuos aislados, disgregados, sobre los cuales se podrá concretar la acción. Se sigue después de una razzia como la que nos ocupa, una costumbre cruel: los niños de corta edad, si los padres han desaparecido, se entregan a diestra y siniestra. Las familias distinguidas de Buenos Aires buscan celosamente estos jóvenes esclavos para llamar las cosas por su nombre.

Desde temprano el blanco interpreta que la mayor dificultad para someter al indio es su concepto de tribu y de familia, es por esto que una de las principales acciones es aislarlo, física y simbólicamente, para completar la dominación.

Mbembe plantea que negro es "una ganga compuesta de tonterías y de fantasías urdidas por Occidente y otras partes del mundo...” (pág. 84) Si bien indio también es un cúmulo de sentidos organizados de forma desordenada hay una intensión reguladora y organizadora propuesta desde el discurso científico. Pero de todas maneras la conclusión es siempre la misma, el negro y el indio son malos, son sucios, son vagos, son feos, son borrachos, son imbéciles y no hay nada que se pueda hacer al respecto así que no vale la pena intentarlo, la ciencia consuela a las almas sensibles explicando las diferencias biológicas que hacen que el indio no pueda aprender y no sienta dolor ni físico ni espiritual.

En su estudio acerca de África el médico Josiah Clark Nott hace uso de cierto lenguaje cientificista para elaborar este punto,

Estas son todas tribus salvajes, poco distintas, en naturaleza física y propensiones morales, a los hotentotes. Cualquier cosa similar a un análisis detallado de ellos no sería más que una inútil repetición de descripciones, que se encuentran en todos los relatos de viajeros, exhibiendo imágenes de las razas más degradadas de la humanidad. En una palabra, el África toda, al sur de los $10^{\circ}$ de latitud norte, muestra una sucesión de seres humanos con su intelecto tan negro como su piel, y con una conformación cefálica que convierte a cualquier esperanza en su mejoramiento en un sueño utópico, filantrópico, pero de alguna manera senil. (Nott, 1855)

La falta de expectativas acerca de su "mejoramiento" tranquiliza al occidental que entiende que no importa no hacer nada ya que no hay nada que valga la pena ser hecho. Uno de los recluidos en el museo fue el cacique Inacayal quién luego de ver morir a su esposa y a su hija se volvió cada vez más taciturno y pasaba sus días sentado sin moverse frente 
a la vitrina que exhibía los restos de su mujer, esto resultaba profundamente extraño para los científicos que trataban de definir el carácter del ex gobernante. Hermann Tate Kate señala que Inacayal “... Era reservado, desconfiado, orgulloso y rencoroso. Comunicativo solamente cuando estaba ebrio. Dormía casi todo el día, discutía fácilmente, muy apático y sin ninguna preocupación por su persona." (Fernández, Alfredo) Llama la atención la sorpresa que genera en Tate Kate el dolor del indio, como si no comprendiera su capacidad de generar vínculos afectivos con su mujer y de sufrir frente a la perdida.

Las crónicas de la época registran la depresión y tristeza que experimentan estos sujetos y como estas características se acentúan con el correr del tiempo en prisión. Pero este registro de las mudanzas anímicas no se interpreta como resultado del accionar del blanco y por consiguiente no es su responsabilidad. En general la explicación que se repite para justificar el ánimo de los prisioneros es su falta de templanza o su natural predisposición al silencio y a la apatía, la incapacidad del indio de sentir entusiasmo frente a las investigaciones que sobre él o sobre sus seres queridos realiza el investigador son tenidas en cuenta como falta de inteligencia. El antropólogo Milcíades Viñati menciona acerca de sus impresiones sobre el cacique Inacayal (Fernández, Alfredo):

Tratar de dar una idea de los caracteres morales de estos indígenas es asunto por demás difícil dada la complejidad de sentimientos que los animaban y que, fácilmente, se trocaban desde la amistosa deferencia a la animadversión violenta. No cabe dudar que las distintas situaciones, por transitorias que fueran, eran origen de reacciones por lo común irrazonadas y siempre desproporcionadas al motivo aparente que las ocasionaba. En estos momentos cruciales es, sin embargo, cuando despojados de todo convencionalismo, dejaban en plana desnudez los sentimientos inferiores y el salvajismo congénito.

\section{Las fotos}

"Por lo tanto, ¿a qué se parece una foto?" nos asalta Soulages, "En todo caso, no al objeto por fotografiar, porque éste es incognoscible, inasible y por tanto infotografiable. Una foto sólo se parece a una foto, ni siquiera al fenómeno visual enfocado. Una música no se parece al canto del mirlo sino a otra música y una pintura no se parece a una montaña sino a otra pintura." (pág. 104)

Susan Sontag aborda el problema de la representación y plantea que "Una fotografía no es meramente el resultado del encuentro entre un acontecimiento y un fotógrafo; fotografiar es un acontecimiento en sí mismo, y un acontecimiento que se arroga derechos cada vez más perentorios para interferir, invadir o ignorar lo que esté sucediendo." (pág. 21) Fotografiar es un acontecimiento porque es algo que sucede, no es algo estático.

Más allá de la especificidad de la fotografía como "huella" de algo que una vez estuvo frente a la cámara (Dubois, 1986) (Soulages, 2010) o como algo que "ha sido" (Barthes, 1982) y de la extendida creencia en los méritos de la fotografía para la captación objetiva de la realidad, la ciencia decimonónica percibe desde temprano la necesidad de sistematizar los 
modos de representación para lograr resultados objetivos que sirvan para producir conclusiones, comparaciones y análisis adecuados para diversos usos. Con esta intención se publicaran textos y se darán debates acerca de las distintos estrategias que se piensan que son más eficientes para la construcción de la imagen fotografía.

En nuestro caso de estudio las fotos nos presentan a los individuos aislados de su entorno físico y social, en la mayoría de estas aparecen solos, representados de frente y de perfil (podía agregarse en algún caso una foto de espaldas), en poses rígidas y estereotipadas que enfatizan la extrañeza de los sujetos frente a el dispositivo fotografico, son muy pocas las fotos en las que los sujetos aparecen cómodos o sonriendo de manera natural.

La invitación a que los sujetos de investigación sean representados de frente y perfil siguiendo una métrica y organización preestablecida, surge de la antropología física, pero se extenderá a la criminalística con mucha rapidez. Marta Penhos (2005) recupera un convenio firmado en 1905 por las policias sudamericanas que estipula lo siguiente:

La fotografía de la cara se tomará en doble ejemplar, uno de frente y otro de perfil en placas de $9 \times 13$, procurando cada policia tomar todas las fotografías a una distancia uniforme, de modo que los tamaños de las imágenes guarden entre sí proporción al tamaño real de los individuos fotografiados; cuidadndo de que la imagen de la cabeza no pase de $32 \mathrm{~mm}$. Medidos de la linea superior del pelo a la base del mentón. (pág. 32-33)

Marta Penhos (2005) en su estudio acerca de la influencia de la ciencia criminologica en la fotografía señala que hubo un cambio en la percepción, “....un viraje en la percepción y representación de los indígenas por parte de la sociedad blanca. Una vez sometidas las tribus del sur, sus miembros ya no aparecen tanto como vehículos del terrorífico peligro de los malones, y lentamente pasan a ser considerados como objetos de estudio." (pág. 24) La utilización que la criminalística hace de la pose con la que son representados los sujetos estudiados por la antropología marca un modo de percepción social de esas imágenes que quedará vinculado a una construcción del otro guiada por un estereotipo negatico. Esto fue estudiado en profundidad por Mercedes García Ferrari en su libro Ladrones conocidos. Sospechosos reservados en donde da cuenta de la reacción del gremio de cocheros cuando se les quiere imponer registrarse fotográficamente siguiendo la construcción de la imagen de la criminalística (con una fotografía de frente y una de perfil), tempranamente este grupo percibe que la construcción fotográfica implica o implará a futuro una criminalización del oficio y es por esto que se oponen iniciando asi una huelga de cocheros.

En relación a esto Ten Kate deja un testimonio muy ilustrativo cuando explica la percepción que los propios sujetos indígenas tienen del dispositivo fotográfico y del trabajo que sobre ellos se propone realizar el científico,

Si bien una docena de los mismos fueron convocados a venir al museo por el director M. Moreno para que yo los midiera, estos araucanos se prestaban a ello de muy mala gana. Raramente, en mi vida de viajero-antropólogo, tuve que tener tanta paciencia como con estos indios. Como con ellos había dos agentes de poli- 
cia, habían escuchado hablar del servicio antropométrico de Bertillion, tal como se lo aplica también en La Plata. Por consecuencia, creían que mis investigaciones tenían alguna relación con la policía y, no queriendo ser tratados como vulgares malhechores, rechazaban someterse a la medición. (Penhos, 2005. pág. 35)

En la mayoría de nuestras fotos los sujetos aparecen vestidos en contra de lo que proponia el método de la Escuela de Antropología de París que sugería enfaticamente que para su mejor observación los sujetos debían aparecer solos, sin ropa y sin objetos que pudieran distraer la mirada del observador. Lo que se busca en estas imágenes son datos que se puedan pensar cuantitativamente y no una construcción estética de la escena.

La capital recordaba haber visto representaciónes pictóricas del indio en el malón, robando y matando al desafortunado blanco, estas fotografías buscan representar al indio de otro modo. La pintura construye narraciones que están influidas por el romantisismo de la época en las que el indio se puede representar tanto como el buen salvaje o como una cruel y brutal amenaza. Esto se deja apreciarse en la fotografía también, los sentidos que abren estas obras no son únicos y de ahí su complejidad.

Cuando Carlos Bruch viaja al Ingenio La esperanza las fotos que se producen ahí muestran a las personas en su espacio natural, en grupos, mostrando atuendos y objetos, no se guia por los estrictos parámetros de la antropología física.

El uso de estos cuerpos en la fotografía tendrá diferentes consecuencias en relación a su circulación. Los álbumes que funcionan como catálogos construidos por científicos con la intención de producir datos exactos circularan en ámbitos académicos donde lo que se busca es medir y comparar, atendiendo a los principios de la fisionomía y de la craneología.

Esta necesidad de optimizar los recursos de la observación y la identificación llevó al desarrollo de diferentes métodos que fueron utilizados por la criminología, la antropología, y la psiquiatría. Uno de ellos es la antropometría. El francés Paul Broca había establecido en 1865 algunas normas para el uso de esta técnica, pero a partir de 1874, en sucesivas reuniones científicas se dieron a conocer varias propuestas alternativas, que, si por una parte traían cierta confusión, por otra indican el creciente interés por un medio cuyo aprovechamiento sería consagrado en el ambiente criminológico por Lombroso en L'uomo delincuente, publicado en 1876. (Penhos, 2005. pág. 29)

Muchas veces las mismas fotos circulan en álbumes vendidos a particulares en América y en Europa que alimentaban la curiosidad acerca del otro enfatizando las diferencias entre estos y las costumbres occidentales. En este caso los consumos se guían más por una mentalidad romántica a la búsqueda de lo exótico y llamativo.

En este caso en los sujetos retratados solos y serios posando ante la cámara, el desnudo enfatiza su falta de contacto con la "civilización occidental" y su incapacidad de comprender las restricciones europeizantes en relación a la presentación pública del cuerpo, la desnudez enfatiza su animalidad, su primitivismo y además, aspecto que no es de menor importancia, la carencia total de manufacturas bellas o productivas como telas, vestidos, 
calzados una industria que siempre fue importante. El que posa se vincula más con lo animal que con lo social que caracteriza al ser humano, estas fotos buscan "... dar al traste con el tejido cultural que mantiene intacta la integridad de estas personas” (Butler, pág. 129) En este caso el corpus con el que trabajamos son fotografías de distintas personas de distintas procedencias y de diferentes edades y jerarquías que son aplanadas y vistas como un solo otro por el ojo de una mirada europeizante que no es capaz de percibir diferencias y matices. En estas fotos se presentan a los sujetos aislados de su entorno, son primeros planos de frente y/o perfil que buscan reproducir una mirada que se pretende objetiva sobre el otro sin dar cuenta de que en realidad el uso de la foto lo está conformando y está generando un sentido con el que miramos a los pueblos originarios hasta el día de hoy, esta conformación que ya perdura más de un siglo se repite por que es eficiente, en donde se une la antropología con la criminalística para catalogar al otro como peligroso e inferior. En la foto científica los fondos son neutros con la intención de que nada distraiga o intervenga en el analisis objetivo del sujeto presentado como especimen, y se va a buscar la manera de prepresentar a las figuras de forma estandarizada para poder establecer comparaciones que otros sujetos de otras latitudes. Para esto los fotografos se valen de reglas o cuadriculas que estandarizan los prosesos.

Las fotos que se han conservado, tomadas en los últimos años del siglo XIX, no son todas iguales, lo que de alguna manera nos permite reconocer en esa multiplicidad un conjunto es cierta intensión de construir un relevamiento de una realidad que se comienza a entender como efímera. Hay una mirada europea que se acerca al continente americano y con una mezcla de interés, sorpresa y superioridad se vincula al otro y de mirarlo le construye un sentido que seguirá siendo fuerte y presente.

Estas fotos que surgen de una campaña militar representan en las imágenes que la lucha sobre los cuerpos es la lucha sobre los territorios, sobre los bienes y sobre las fuerzas productivas.

Todavía, igual que hace ya tantos años, entendemos que la apropiación no puede ser realizada libremente sino que tenemos que construir un discurso y una imagen que lo refuerce. Se necesita un discurso que autorice a someter a un sujeto que ha sido avasallado en su sentido más básico, su sentido humano. Tal y como plantea Butler la operación que se hace en la imagen y en el discurso obtura la posibilidad de pensar un nosotros, construye un otro totalmente escindido y define con argumentos cientificistas que este es jerárquicamente inferior.

\section{Lista de Referencias bibliográficas}

Aranda, D. (10 de octubre de 2011). El Estado se construyo sobre un genocidio. Página 12. Barthes, R. (1982). La cámara lúcida. Argentina: Paidós.

Butler, J. (2010). Marcos de guerra. Las vidas lloradas. Argentina: Paidós.

Butler, J. (2018). Cuerpos que importan. Argentina: Paidós.

Dubois, P. (1986). El acto fotográfico. De la representación a la Recepción. España: Paidos Comunicación. 
Fernandez, Alfredo (26/8/2016) Inakayal y su agonía de 100 años. Cosecha Roja. URL: http:// cosecharoja.org/inakayal-y-su-agonia-de-100-anos/

Ferrari, M. G. (2010). Ladrones conocidos/Sospechosas reservados. Identificación policial en Buenos Aires, 1880-1905. Buenos Aires: Prometeo.

Karina Oldani, M. A. (30 de junio de 2011). Las muertes invisibilizadas del Museo de La Plata. Corpus [En línea], Vol 1, No 1 | 2011 consultado el 26 octubre 2018. URL : http:// journals.openedition.org/corpus.

Mbembe, A. (2016). Crítica de la razón negra. Buenos Aires: Futuro Anterior Ediciones.

Penhos, M. (2005). Arte y Antropología en la Argentina. En Frente y perfil. Una indagación acerca de la fotografía en las prácticas antropológicas y criminológicas en Argentina a fines del siglo XIX y priincipios del XX. (págs. 17-64). Buenos Aires: Fundación Espigas.

Penhos, M. (2005). Ver, conocer, dominar. Imágenes de sudamerica a fines del siglo XVIII. Argentina: Siglo XXI Editores.

Penhos, M. (2018). Paisaje con figuras. La invención de Tierra del Fuego a bordo del Beagle (1826-1836). Argentina: Ampersand.

Pratt, M. L. (1997). Ojos Imperiales. Literatura de viajes y transculturación. Argentina: Universidad Nacional de Quilmes.

Sorlin, P. (2004). El "siglo" de la imagen analógica. Los hijos de Nadar. Buenos Aires: La marca editora.

Soulages, F. (2010). Estética de la Fotografía. Argentina: La Marca editora.

Tagg, J. (1988). El peso de la representación. Ensayos sobre fotografías e historias. Barcelona: Editorial Gustavo Gili.

Tell, V. (2017). El lado visible. Fotografía y progreso en la Argentina a fines del siglo XIX. Argentina: UNSAM Edita.

\begin{abstract}
Historically, different disciplines have used photography to show a step forward in research and the message they want to deliver. Photography, on the other hand, has been at service of text and thoughts, without been deeply considered as a singular object of studying.

The photos which we intend to work with haven 't been lucky either. From the moment they were created, their importance in relation to the represented object has been subject of debate, meaning how faithfully were other's body characteristics printed on the photos for the investigator to focus on later.

Carlos Bruch's photos about different native communities (both in the north and the south of Argentina) show an understanding of photography, but also allows us to think of the photographer's deeply conception regarding the country inhabitants, as well as science as a way to order and comprehend the world.
\end{abstract}

Keywords: Photographic uses - message - debate 
Resumo: Historicamente diferentes disciplinas utilizaram a fotografia para ilustrar seus avanços de pesquisas e seus discursos, fotografia tem vindo a servir o texto e a reflexão enquanto que aprofunda-lo como um objeto de estudo independente. Fotos com que trabalhamos já não tinha um tipo muito diferente, desde o momento da sua criação discutido sobre o que era o lugar que ocupam em relação ao objeto representado, é como fielmente ou impresso na imagem as características do corpo do outros interessados pesquisadores então reconheceram no seu estudo.

Palavras chave: Fotografia - objeto representado - estudo

[Las traducciones de los abstracts fueron supervisadas por el autor de cada artículo] 